\title{
Molecular Analysis Revealed that Namibian Cheetahs (Acinonyx Jubatus) are definitive hosts of a so far undescribed Besnoitia species
}

\section{Gereon Schares ( $\sim$ Gereon.Schares@fli.de)}

Friedrich-Loeffler-Institut https://orcid.org/0000-0002-3217-289X

Maike Joeres

Friedrich-Loeffler-Institut Bundesforschungsinstitut für Tiergesundheit: Friedrich-Loeffler-Institut Bundesforschungsinstitut fur Tiergesundheit

Franziska Rachel

Friedrich-Loeffler-Institut Bundesforschungsinstitut für Tiergesundheit: Friedrich-Loeffler-Institut Bundesforschungsinstitut fur Tiergesundheit Mareen Tuschy

Friedrich-Loeffler-Institut Bundesforschungsinstitut für Tiergesundheit: Friedrich-Loeffler-Institut Bundesforschungsinstitut fur Tiergesundheit Gábor Á. Czirják

Leibniz Institut für Zoo und Wildtierforschung eV: Leibniz Institut fur Zoo und Wildtierforschung eV

Pavlo Maksimov

Friedrich-Loeffler-Institut Bundesforschungsinstitut für Tiergesundheit: Friedrich-Loeffler-Institut Bundesforschungsinstitut fur Tiergesundheit Franz J. Conraths

Friedrich-Loeffler-Institut Bundesforschungsinstitut für Tiergesundheit: Friedrich-Loeffler-Institut Bundesforschungsinstitut fur Tiergesundheit Bettina Wachter

Leibniz Institut für Zoo und Wildtierforschung eV: Leibniz Institut fur Zoo und Wildtierforschung eV

\section{Research Article}

Keywords: Besnoitia spp., Namibia, real-time PCR, metatheria, eutheria, placental mammals, marsupial mammals, phylogeny, Acinonyx jubatus

Posted Date: February 19th, 2021

DOI: https://doi.org/10.21203/rs.3.rs-235843/v1

License: @) (1) This work is licensed under a Creative Commons Attribution 4.0 International License. Read Full License

Version of Record: A version of this preprint was published at Parasites \& Vectors on April 14th, 2021. See the published version at https://doi.org/10.1186/s13071-021-04697-3. 


\section{Abstract}

Background: Besnoitia darlingi, B. neotomofelis and B. oryctofelisi are closely related coccidian parasites with felids as definitive hosts. These parasites use a variety of animal species as intermediate hosts. North American opossums (Didelphis virginiana), North American southern plains woodrats (Neotoma micropus) and South American domestic rabbits (Oryctolagus cuniculus) are intermediate hosts of B. darlingi, B. neotomofelis and B. oryctofelisi, respectively. Based on conserved regions in the Internal Transcribed Spacer-1 (ITS-1) sequence of the ribosomal DNA (rDNA), a real-time PCR for a sensitive detection of these Besnoitia spp. in tissues of intermediate hosts and faeces of definitive hosts has recently been established. Available sequence data suggest that species such as $B$. akodoni and $B$. jellisoni are also covered by this real-time PCR. It has been hypothesised that additional Besnoitia spp. exist worldwide, which are closely related to $B$. darlingi or $B$. darlingi-like parasites ( $B$. neotomofelis, $B$. oryctofelisi, $B$. akodoni or $B$. jellisoni). Related but not closely related to these species is $B$. besnoiti, the cause of bovine besnoitiosis.

Methods: Faecal samples from two free-ranging cheetahs (Acinonyx jubatus) from Namibia that had previously tested positive for coccidian parasites by coproscopy, were used for this study. A conventional PCR verified the presence of coccidian parasite DNA. To clarify the identity of these coccidia, the faecal DNA samples were further characterised by species-specific PCRs and Sanger sequencing.

Results: One of the samples tested positive for $B$. darlingi or $B$. darlingi-like parasites by real-time PCR, while no other coccidian parasites including Toxoplasma gondii, Hammondia hammondi, H. heydorni, B. besnoiti, and Neospora caninum were detected in the two samples. The rDNA of the B. darlingilike parasite was amplified and partially sequenced. Comparison with existing sequences in GenBank revealed a close relationship to other Besnoitia spp., but showed also clear divergences.

Conclusions: Our results suggest that a so far unknown Besnoitia species exists in Namibian wildlife, which is closely related to $B$. darlingi, $B$. neotomofelis, $B$. oryctofelisi, $B$. akodoni or $B$. jellisoni. The cheetah appears to be the definitive host of this newly discovered parasite, while a prey species of the cheetah may act as intermediate hosts.

\section{Background}

Besnoitia darlingi, B. neotomofelis, and B. oryctofelisi are closely related coccidian parasites, for which domestic cats have been ascertained as definitive hosts [1, 2, 3, 4]. Bobcat (Lynx rufus) was identified as definitive host of B. darlingi in the wild [5]. Besnoitia darlingi uses a marsupial, the North American opossum (Didelphis virginiana) as its intermediate host [5]. In contrast, B. neotomofelis and B. oryctofelisi have been described in placental mammals, i.e. in the North American Southern Plains woodrat (Neotoma micropus) and in domestic rabbits from South America (Oryctolagus cuniculus), respectively [2, 4, 6]. Besnoitia akodoni, another closely related Besnoitia species, was described in a placental mammal in South America, the rodent Akodon montensis as intermediate host [7]. Another Besnoitia sp., B. jellisoni was described in North American white-footed deer mouse (Peromyscus maniculatus), and three species of kangaroo rats (Dipodomys species) as intermediate hosts $[8,9]$. In contrast to $B$. darlingi, $B$. neotomofelis, and $B$. oryctofelisi, the definitive hosts of $B$. jellisoni or $B$. akodoni are unknown. Domestic cats, other carnivorous mammals, various birds, and snakes have been excluded as final hosts of $B$. jellisoni $[10,11]$. Further reports suggest the presence of similar Besnoitia spp. parasites in New Zealand, Australia, Japan and Kenya [12, 13, 14, 15]. Moreover, for $B$. wallacei, first described on Oahu, Hawaii, in a domestic cat (i.e. its definitive host), experimental studies suggested rodents (mice, rats) as appropriate intermediate hosts [10].

It was therefore recently argued that other, so far unknown, Besnoitia species may exist in other parts of the world [16]. The high level of conservation in the Internal Transcribed Spacer-1 (ITS-1) sequence of the ribosomal DNA (rDNA) among related species of $B$. darlingi and $B$. darlingi-like species ( $B$. neotomofelis, B. oryctofelisi B. akodoni, B. jellisoni) was utilised to establish primers and a probe for the detection of such Besnoitia spp. parasites in their intermediate (e.g. rodents, lagomorphs and marsupials) or in definitive hosts (e.g. wild felids or canids) [16]. This real-time PCR is not able to detect Besnoitia spp. of cattle, goats, donkeys and horses, and caribou and reindeer, such as B. besnoiti, B. caprae, B. bennetti and B. tarandi, respectively [16].

Our previous work suggested the presence of Toxoplasma gondii in most and B. besnoiti and Neospora caninum in few of 12 Namibian wildlife species, including six Feliformia, four Caniforma and two Ruminantia [17]. Felids, including cheetahs (Acinonyx jubatus), are known as definitive hosts of $T$. gondii, but for $B$. besnoiti, the causative agent of bovine besnoitiosis, the definitive host is unknown, although wild felids have been discussed as candidates [17, 18]. Since morphological identification of coccidian parasites is challenging, we examined with molecular methods the faeces collected from the ampulla recti of two free-ranging cheetahs for $B$. besnoiti. In a previous study, these two cheetahs had been identified positive for coccidian oocysts by coproscopy [19].

\section{Methods}

\subsection{DNA extraction}

In this study, we used faecal samples from two free-ranging female cheetahs, one sub-adult and one adult, from farmland in central Namibia. The animals had tested positive for coccidian parasites by coproscopy [19]. Capture and handling of the animals, sample collection, transport and storage has previously been described [17, 19, 20]. The Quick-DNA Fecal/Soil Microbe DNA Miniprep Kit (Zymo Research Europe GmbH, Freiburg, Germany) was used to extract DNA from $200 \mathrm{mg}$ aliquots according to the manufacturer's recommendations. From the faecal sample of the sub-adult female, two aliquots were available, which were independently extracted. Extraction typically yields $100 \mu \mathrm{l}$ DNA per faecal sample [16].

\subsection{Endpoint PCR}


To test for coccidian parasites, a PCR was performed using the common apicomplexan small subunit ribosomal DNA (18S rDNA) primers COC-1 and COC-2 $[21,22]$. Hammondia heydorni DNA was tested using the primers JS4/JS5 as described [23, 24]. Due to the high level of sequence identity in the rDNA target, the primer pair JS4/JS5 was expected to amplify also DNA of $H$. triffitae, a coccidian parasite using foxes as definitive hosts $[25,26,27]$.

For the identification of coccidian parasites by Sanger sequencing, rDNA was amplified by end-point PCR using primer pairs (Fig.1) as previously published $[23,28,29]$ and listed in Additional file 1: Table S1.

For all PCRs, primers were used at a final concentration of $0.5 \mathrm{mM}$ and dNTPs at a final concentration of $250 \mathrm{mM}$ each (Stratec Molecular GmbH, Berlin, Germany). Taq polymerase (Stratec Molecular $\mathrm{GmbH}$, Berlin, Germany) had a final concentration of $1 \mathrm{U} / 25 \mu$ applying the buffer system supplied with the enzyme. The PCR cycling conditions were $94^{\circ} \mathrm{C}$ for $5 \mathrm{~min}$, followed by 10 cycles of $56^{\circ} \mathrm{C}$ (with $0.5^{\circ} \mathrm{C}$ decrement per cycle after the $1^{\text {st }} \mathrm{Cycle}$ ) for $1 \mathrm{~min}, 72{ }^{\circ} \mathrm{C}$ for $1 \mathrm{~min}$, and $94^{\circ} \mathrm{C}$ for $1 \mathrm{~min}$, followed by 40 cycles of $51^{\circ} \mathrm{C}$ for $1 \mathrm{~min}, 72^{\circ} \mathrm{C}$ for $1 \mathrm{~min}$, and $94{ }^{\circ} \mathrm{C}$ for 1 min. The PCR ended with an incubation at $51^{\circ} \mathrm{C}$ for 1 min and a final extension at $72^{\circ} \mathrm{C}$ for 5 min.

\subsection{Real-time PCRs}

Real-time PCRs were used to test for T. gondii, H. hammondi, B. besnoiti, B. darlingi and B. darlingi-like parasites, or N. caninum. T. gondii was examined as previously reported targeting the TgREP-529 [30, 31]. H. hammondi was diagnosed using a recently published real-time PCR targeting HhamREP-529 [22]. N. caninum DNA was examined using a previously published real-time PCR targeting Nc5 [31]. In case of $B$. besnoiti, a fragment of the ITS-1 region in the rDNA was amplified as described (BbRT1; [32]). For B. darlingi and B. darlingi-like parasite, a recently published real-time PCR designated BdanjoRT1 PCR was applied [16]. For the detection of $N$. caninum DNA a previously published real-time PCR [31, 33] was used.

To monitor inhibition of the real-time PCRs, a heterologous plasmid with DNA sequences resembling the enhanced green fluorescent protein (EGFP) gene [34] was added to the reaction mix in all real-time PCRs except for $N$. caninum. The internal control PCR included the primers EGFP1-F, EGFP2-R, and the probe EGFP1 [22]. A 712 bp fragment of the EGFP gene was amplified and cloned into the pGEM-Teasy standard cloning vector (Promega, Walldorf, Germany) in reverse orientation to obtain the internal control (IC) DNA (pGEM-EGFP2-rev). The amount of the IC DNA added to each reaction was adjusted so that it resulted in a cycle of transition (Ct) value of approximately 32 in the real-time PCR.

Reactions were performed in a final volume of $20 \mu \mathrm{l}$ using a commercial master mix (PerfeCTa MultiPlex qPCR ToughMix, Quantabio, VWR International, Darmstadt, Germany) and a CFX384 instrument (Biorad Laboratories GmbH, Munich, Germany). Primers and probes were purchased from MWG-Biotech (Ebersberg, Germany). Standard concentrations for primers (500 nM) and probes (100 nM, target specific primers; $160 \mathrm{nM}$, EGFP1) were applied. The cycling conditions in real-time PCR were $95.0^{\circ} \mathrm{C}$ ( $5 \mathrm{~min}$, initial denaturation), followed by 45 cycles, during which the samples were first incubated at $95.0{ }^{\circ} \mathrm{C}$ for $10 \mathrm{~s}$ and then at $60.0^{\circ} \mathrm{C}$ for $30 \mathrm{~s}$. After each cycle, the light emission by the fluorophore was measured. Real-time PCR results were analysed using the CFX manager software Version1.6 (Biorad Laboratories GmbH, Munich, Germany).

\subsection{Cloning}

For Sanger sequencing of amplification products, bands of the expected size were excised from agarose gels and purified with a commercial kit (NucleoSpin ${ }^{\circledR}$ Gel and PCR Clean-up, Macherey-Nagel, Düren, Germany), following the manufacturer's instructions. Purified amplification products were then cloned into a commercially available vector (pGEM®-T Easy Vector System I, Promega, Mannheim, Germany) and used to transform chemically competent Escherichia coli (OneShot TOP10, Thermo Fisher Scientific, Langenselbold, Germany). The transformed E. coli were cultivated and the plasmid DNA was subsequently collected using a commercial kit (QIAprep Spin Miniprep Kit, Qiagen, Hilden, Germany) according to the manufacturer's instructions. Sequencing was performed using the BigDye Terminator v1.1 Cycle Seq. Kit (Thermo Fisher Scientific, Langenselbold, Germany) and passage through NucleoSEQ Columns (Macherey-Nagel, Düren, Germany) for cleaning up nucleic acids, in an ABI 3130 capillary sequencer (Thermo Fisher Scientific, Langenselbold, Germany).

The forward and reverse sequences were aligned, if necessary trimmed based on primer sequence information and the consensus sequences for the individual cloned amplification products compared to sequences stored in GenBank, EMBL, DDBJ, or RefSeq using BLASTn with standard conditions.

\subsection{Phylogenetic analysis}

The evolutionary history based on ITS-1 rDNA sequences was inferred using the Maximum Parsimony (MP) method. The number of base substitutions per site between sequences included into the analysis was termed "pairwise distance" or "evolutionary divergence" in the following. The MP tree was obtained using the Subtree-Pruning-Regrafting (SPR) algorithm [35] with search level 0, in which the initial trees were obtained by the random addition of sequences (10 replicates). All codon positions $\left(1^{\text {st }}, 2^{\text {nd }}, 3^{\text {rd }}\right.$, Noncoding) were included. Evolutionary analyses were conducted in MEGA X [36].

\section{Results}

\subsection{Polymerase chain reactions (PCRs) for coccidian parasites}

The observed parasitic structures, previously diagnosed microscopically as coccidia [19], were confirmed by a positive reaction in an 18S rDNA-based endpoint COC-1/COC-2 PCR for both samples of the two cheetahs (one subadult and one adult female). Species-specific PCRs were negative for $T$. gondii, $H$. hammondi, and B. besnoiti. The unlikely presence of $N$. caninum or $H$. heydorni was also excluded by real-time or endpoint PCR. Using a real-time PCR

Page 3/10 
established to detect $B$. darlingi and $B$. darlingi-like parasites [16], we observed in both sample aliquots of the sub-adult female cheetah a positive signal (Ct 28.3 or 31.9 ). This suggests that genomes equivalent to 10-100 tachyzoites were present in $10 \mu \mathrm{l}$ of the $100 \mu \mathrm{l}$ DNA extracted from this faecal sample. In the sample of the adult female cheetah no signal was observed, although the IC real-time PCR revealed no inhibition.

\subsection{Characterisation of $18 \mathrm{~S}$ and ITS-1 rDNA sequences of a Besnoitia sp.-like parasite}

The positive $B$. darlingilike real-time PCR suggested either the presence of $B$. darlingi in the faeces of the positive cheetah, however this is unlikely because $B$. darlingi use marsupials as intermediate hosts which are not present in Africa. Most likely, the result suggested the presence of oocysts of another, possibly not yet known, Besnoitia species. To identify this parasite, we partially characterised its rDNA using overlapping amplification products for parts of the 18S rDNA, the ITS-1 rDNA and parts of the 5.8S rDNA (Fig. 1; Table 1; Additional file 1: Table S1). The sequences of cloned amplicons were analysed by BLASTn with recording the five top species hits using BLASTn suite (Max Score). The amplicons of four different targets, using the primer pairs JS4-TIM11, 18S-5F-TIM11, BbGS4F-BdanjoRev, and BbGS5F-BbGS5R revealed sequences related to the candidate of a Besnoitia species (Table 1). These were $B$. darlingi, $B$. neotomofelis, B. oryctofelisi, B. jellisoni, B. akodoni, B. besnoiti, B. bennetti, B. caprae, and B. tarandi, with percent identities of $>90 \%$ up to $99.54 \%$ among the top species hits in BLASTn (Table 1, Besnoitia sp.-related). With the exception of the BbGS4F-BdanjoRev cloned sequences, $B$. darlingi sequences (GenBank, EMBL, DDBJ, RefSeq) ranked always first (Table 1), which suggests that a parasite closely related to $B$. darlingi or $B$. darlingilike parasites had been excreted as oocysts by the Namibian cheetah. The sequences of JS4-TIM11 ( $n=6), 18 S-5 F-T I M 11(n=3)$ and BbGS4F-BdanjoRev ( $n=3)$ clones, i.e. clones covering the ITS-1 sequence were aligned and the consensus sequence stored at GenBank (MW468050) using the parasite isolate designation "Besnoitia-acinonyx". The $B$. darlingi-like sequences amplified by BbGS5F-BbGS5R (i.e. a part of the 18S rDNA) was also stored in GenBank (MW559556).

Some of the remaining sequences had only coccidian parasites among the first five species hits. However, these species hits were dominated by Cystoisospora spp. This may suggest that Cystoisospora spp. had been present in the faecal samples in addition to the $B$. darlingi-like parasites (Table 1 , coccidia-related).

\subsection{Phylogenetic relationships to "Besnoitia-acinonyx"}

Based on the ITS-1 rDNA sequence, the possible phylogenetic relationships of the newly described species and represented by the DNA isolate, here termed "Besnoitia-acinonyx", to other Besnoitia spp., namely B. darlingi, B. neotomofelis, B. oryctofelisi, B. akodoni, B. jellisoni and B. besnoiti, but also to T. gondii, $H$. heydorni, H. triffitae, and N. caninum were assessed. The ITS-1 sequence placed "Besnoitia-acinonyx" between those of $B$. darlingi, $B$. darlingi-like parasites, and $B$. besnoiti (Fig. 2). Estimates of evolutionary divergence revealed a close relationship to B. darlingi, B. neotomofelis, B. oryctofelisi, B. akodoni and $B$. jellisoni (pairwise distances < 0.1 ; Table 2) and a larger distance to $B$. besnoiti (distance 0.234 ; Table 2). Among the remaining coccidia tested, T. gondii showed a higher distance to "Besnoitia-acinonyx" (0.595, Table 2) than N. caninum (0.544, Table 2). Interestingly, T. gondii and N. caninum showed a closer relationship to "Besnoitia-acinonyx" than to all remaining Besnoitia spp. except B. besnoiti (Table 2). In addition, B. besnoiti was closer to "Besnoitia-acinonyx" (0.234, Table 2) than to any other Besnoitia sp. examined (0.294-0.268; Table 2). Identities of the ITS-1 rDNA of "Besnoitia-acinonyx" with $B$. darlingi and the $B$. darlingilike parasites were 89.7-90.1\% (B. darlingi), 89.7\% (B. oryctofelisi), 88.9\% (B. akodoni), and 86.9\% (B. jellisoni and B. neotomofelis).

\section{Discussion}

In this study, we examined archived faecal samples of two free-ranging cheetahs from farmland in central Namibia. Coccidian parasites had been identified by coproscopy in these samples previously [19]. Using a coccidia-specific PCR, the microscopic observations were confirmed for both animals.

We originally expected T. gondii or H. hammondi in the cheetahs, as these parasites are known to use felids as definitive hosts [37]. Antibodies against the tachyzoite stage of $B$. besnoiti had been detected in blue wildebeest (Connochaetes taurinus) and lions (Panthera leo) in Namibia by serology [17]. Thus, in addition, we suspected that $B$. besnoiti might be present in faecal samples of Namibian cheetahs because felids might be a definitive (and/or intermediate) host of $B$. besnoiti $[17,18]$. In southern Africa, the existence of $B$. besnoiti, which uses cattle as intermediate hosts, has long been known (summarised in [38]). B. besnoitilike parasites were previously isolated from or observed in prey animals of cheetah, such as blue wildebeest, impala (Aepyceros melampus), and kudu (Tragelaphus strepsiceros) in South Africa [39].

For reasons of completeness, DNA extracted from the faecal samples was also examined for $N$. caninum and $H$. heydorni, although these are parasites of dogs, dingoes, wolves or coyotes [27, 40] and for $B$. darlingi, which uses marsupials as intermediate hosts, and related parasites [16].

Our previously developed real-time PCR, established to identify $B$. darlingi, $B$. neotomofelis, $B$. oryctofelisi, B. akodoni, and $B$. jellisoni in intermediate and definitive hosts, tested positive with two sample aliquots of one cheetah (Ct 28.3 and Ct 31.9). When this newly developed real-time PCR was reported, we hypothesised that further $B$. darlingi-related parasites might exist worldwide and might be picked up by this PCR [16]. Since all $B$. darlingi-like parasites known so far were detected in North or South America, it was unlikely that the $B$. darlingilike PCR signal that was observed in the faeces of the cheetah belonged to B. darlingi or one of the American B. darlingi-like parasites. Therefore, this study reports first evidence for the existence of an additional Besnoitia sp. in southern Africa.

A part of the rDNA (18S rDNA) and in particular the ITS-1 rDNA sequence of this parasite was characterised in more detail. In analogy to other coccidian parasites such as T. gondii, we expected that the rDNA sequence was present more than 100-times in the genome of a single parasite organism [41], which makes the rDNA gene and particularly the ITS-1 region a sensitive target for species identification. Since there were no purified oocysts from the faecal samples available, it was difficult to identify or amplify Besnoitia sp. DNA selectively from the plethora of organisms (most likely bacteria and fungi) present

Page $4 / 10$ 
in the faecal samples. The morphological description of the contents of this faecal sample had reported oocysts of approximately $18 \mathrm{x} 18 \mu \mathrm{m}$ in size (Seltmann et al., unpublished data). This suggested that in addition to oocysts of $B$. darlingi-like parasites with an expected size of $10 \times 12 \mu \mathrm{m}(B$. darlingi, [1, 5]), $11 \times 12 \mu \mathrm{m}$ (B. oryctofelisi, [1, 2]), or $13 \times 14 \mu \mathrm{m}$ (B. neotomofelis, [2]), other coccidian parasites, probably Cystoisospora sp., were also present in the sample. Oocysts with a diameter of $10-14 \mu \mathrm{m}$ (expected for Besnoitia sp.) had not been reported in the previous coproscopy study [19] but may have been overlooked. Thus, future studies are necessary to isolate oocysts of this parasite and to determine the oocysts size of this $B$. darlingi-related parasite reliably. In addition to the oocyst sizes observed, the sequences of $18 \mathrm{~S}$ rDNA fragments amplified suggest that Cystoisospora sp. were also present in these faeces. However, the observation of such sequences is not a final prove of the existence of Cystoisospora sp., because 18S rDNA sequences are largely conserved and particular sequence fragments of the 18S rDNA can belong to many different coccidian parasites [42]. Further, a substantial number of sequences clearly showed the presence of fungi or bacteria, which need to be separated from those sequences, which were unambiguously in line with those of Besnoitia spp. or other coccidia.

As several organisms (including other coccidia) may have been present in the faeces, we concentrated on sequences that belonged unambiguously to $B$. darlingi-like parasites. The BdanjoRev primer [16], which had been applied in the $B$. darlingi real-time PCR, played in combination with the BbGS4F primer [28] a central role in the identification of the correct Besnoitia-like rDNA sequences [16]. Using the previously published primer pair JS4 [23] and TIM11 [29], as well as the newly established primer $18 \mathrm{~S}-5 \mathrm{~F}$ in combination with TIM11, we exclusively observed $B$. darlingi-like sequences, which we aligned and made available as a provisional rDNA sequence of "Besnoitia-acinonyx" (MW468050).

The ITS-1 region of the rDNA Besnoitia spp. of New World marsupials, rodents, and domestic rabbits shows only a few differences [5, 43]. The ITS-1 rDNA sequence of the Besnoitia sp. observed in the Namibian cheetah was similar to previously described ITS-1rDNA sequences, but differed from all $B$. darlingi and B. darlingi-like sequences described so far. Identities of the ITS-1 rDNA of "Besnoitia-acinonyx" with $B$. darlingi and $B$. darlingi-like parasites were $\leq 90 \%$ (i.e., 89.7-90.1\% (B. darlingi), 89.7\% (B. oryctofelisi), 88.9\% (B. akodoni) and $86.9 \%$ (B. jellisoni and B. neotomofelis)). Thus, it appears to be justified to conclude that this sequence belongs to a so far unknown Besnoitia sp. that uses the cheetah as its definitive host. Since no free-ranging marsupials exist in Africa, rodent or lagomorph species, which are prey for cheetahs, probably serve this parasite as intermediate hosts. In analogy to the South American $B$. oryctofelisi, lagomorphs such as the Cape hare (Lepus capensis), the Savanna hare (L. microtis), or the Scrub hare (L. saxatilis) may represent suitable intermediate hosts.

The ITS-1 rDNA sequence of "Besnoitia-acinonyx" suggested a closer relationship to the American B. darlingi and B. darlingi-like parasites then to B. besnoiti, which infects cattle and probably also antelopes in southern Africa. This finding suggests that all $B$. darlingi or $B$. darlingilike parasites, regardless of their American or African origin and their ability to infect marsupials or placental mammals have a common ancestor, which evolved, when the South American and the African continents were not yet disconnected, i.e. 100-200 million years ago. Most likely, this common ancestor evolved together with marsupial and placental mammalian animals, which started to separate also around this time [44]. Marsupial mammals are the closest living relatives to placental mammals; they share a common ancestor that lived approximately 130 million years ago [44].

No species of the genus Besnoitia has been observed in Australian marsupials such as kangaroos (Family Macropodidae) and possums (suborder Phalangeriformes). These species have evolved from the South American marsupials and probably reached the Australian continent via Antarctica, when it was not yet separated from South America. Australia lacked felids as definitive hosts for a long time [45], which may be the reason why Besnoitia spp. may have only recently (i.e. for less than the past 200 years) established on this continent and were reported in rats as intermediate and cats as definitive hosts [13]. The presence of Besnoitia spp. in Australian marsupials might still be possible, as Besnoitia spp. infections might have been established, even in absence of felids, if they are able to use other unknown species as definitive hosts.

\section{Conclusion}

Molecular analysis of a faecal sample revealed that Namibian cheetah (Acinonyx jubatus) is most likely a definitive host of a newly described Besnoitia species. This species is closely related to $B$. darlingi and other related Besnoitia spp. parasites of rodents and lagomorphs. Future studies are needed to identify its natural intermediate host in southern Africa, which most likely is a common prey of the Namibian cheetah. Hares, rabbits, and rodents represent possible intermediate host candidates to be further examined.

\section{Abbreviations}

ITS-1 rDNA - internal transcribed spacer-1 ribosomal DNA

SSU-rDNA - small subunit ribosomal DNA

MP - Maximum Parsimony

\section{Declarations}

\section{Acknowledgements}

We would like to thank the Ministry of Environment, Forestry and Tourism in Namibia for permission to conduct research in their country and to the farmers of the Seeis conservancy for their collaboration and help. We are grateful to S.K. Heinrich, J. Melzheimer, B. Wasiolka for sample collections in the field and to F. Webster and S.C. Martins Ferreira for the coproscopical analysis.

\section{Consent for publication}

Not applicable. 
Data supporting the conclusions of this article are included within the article and its additional files. The raw datasets used and analysed for the present study are available from the corresponding author upon reasonable request.

\section{Competing interests}

The authors declare that they have no competing interests.

\section{Funding}

MJ, PM and GS are part of the TOXOSOURCES consortium, supported by funding from the European Union's Horizon 2020 Research and Innovation programme under grant agreement No 773830: One Health European Joint Programme. BW and GÁC are funded by the DFG Research Training Group (GRK) 2046 "Parasite Infections: From Experimental Models to Natural Systems", by the Messerli Foundation, Switzerland, and by the Leibniz Institute for Zoo and Wildlife Research, Germany.

\section{Authors' contributions}

GS, BW and GÁC designed the study. BW, MJ, FR, PM and GS collected the data. MJ, MT and GS performed the experiments and analysed the samples. GS analysed the data. BW, PM, FR, MJ and GS interpreted the data. GS, BW, GÁC, MJ and FJC made major contributions to the writing of the manuscript. All authors read and approved the final manuscript.

\section{Ethics approval and consent to participate}

All experimental procedures, including animal immobilisation and sample collection, were approved by the Internal Ethics Committee of the Leibniz Institute for Zoo and Wildlife Research (Leibniz-IZW) (permit number 2002-04-01) and authorised by the Ministry of Environment, Forestry and Tourism of Namibia (permit numbers 1514/2011 and 1689/2012). Samples were transported to Germany in full compliance with the Convention on International Trade in Endangered Species (CITES). All experiments were carried out in compliance with the approved guidelines of the IZW and the laws of Germany and Namibia.

\section{References}

1. Dubey JP, Sreekumar C, Lindsay DS, Hill D, Rosenthal BM, Venturini L, et al. Besnoitia oryctofelisin. sp. (Protozoa: Apicomplexa) from domestic rabbits. Parasitology. 2003;126 Pt 6:521-39.

2. Dubey JP, Yabsley MJ. Besnoitia neotomofelis n. sp. (Protozoa: Apicomplexa) from the southern plains woodrat (Neotoma micropus). Parasitology. 2010;137 12:1731-47.

3. Smith DD, Frenkel JK. Besnoitia darlingi (Protozoa: Toxoplasmatinae): cyclic transmission by cats. J Parasitol. 1977;63 6:1066-71.

4. Smith DD, Frenkel JK. Besnoitia darlingi (Apicomplexa, Sarcocystidae, Toxoplasmatinae): transmission between opossums and cats. J Protozool. 1984;31 4:584-7.

5. Verma SK, Cerqueira-Cezar CK, Murata FHA, Lovallo MJ, Rosenthal BM, Dubey JP. Bobcats (Lynx rufus) are natural definitive host of Besnoitia darlingi. Vet Parasitol. 2017;248:84-9.

6. Venturini L, Petruccelli M, Piscopo M, Unzaga JM, Venturini MC, Bacigalupe D, et al. Natural Besnoitia sp. infection in domestic rabbits from Argentina. Vet Parasitol. 2002;107 4:273-8.

7. Dubey JP, Sreekumar C, Rosenthal BM, Lindsay DS, Grisard EC, Vitor RW. Biological and molecular characterization of Besnoitia akodoni n.sp. (Protozoa: Apicomplexa) from the rodent Akodon montensis in Brazil. Parassitologia. 2003;45 2:61-70.

8. Ernst JV, Chobotar B, Oaksec, Hammond DM. Besnoitia jellisoni (Sporozoa: Toxoplasmea) in rodents from Utah and California. J Parasitol. 1968;54 3:545-9.

9. Frenkel JK. Infections with organisms resembling Toxoplasma, together with the description of a new organism: Besnoitia jellisoni. Atti del VI congresso internationale di microbiologia. 1953:426-37.

10. Frenkel JK. Besnoitia wallacei of cats and rodents: with a reclassification of other cyst-forming isosporoid coccidia. J Parasitol. 1977;63 4:611-28.

11. Wallace GD, Frenkel JK. Besnoitia species (Protozoa, Sporozoa, Toxoplasmatidae): recognition of cyclic transmission by cats. Science. $1975 ; 188$ 4186:369-71.

12. Ito S, Tsunoda K, Shimura K. Life cycle of the large type of Isospora bigemina of the cat. Natl Inst Anim Health Q (Tokyo). $1978 ; 18$ 2:69-82.

13. Mason RW. The discovery of Besnoitia wallacei in Australia and the identification of a free-living intermediate host. Z Parasitenkd. 1980;61 2:173-8.

14. McKenna PB, Charleston WA. Coccidia (Protozoa: Sporozoasida) of cats and dogs. III. The occurrence of a species of Besnoitia in cats. N Z Vet J. 1980;28 6:120-2.

15. Ng'ang'a CJ, Kanyari PW, Munyua WK. Isolation of Besnoitia wallacei in Kenya. Vet Parasitol. 1994;52 3-4:203-6.

16. Schares G, Dubey JP, Rosenthal B, Tuschy M, Bärwald A, Conraths FJ. Sensitive, quantitative detection of Besnoitia darlingi and related parasites in intermediate hosts and to assess felids as definitive hosts for known and as-yet undescribed related parasite species. International journal for parasitology Parasites and wildlife. 2020;11:114-9.

17. Seltmann A, Schares G, Aschenborn OHK, Heinrich SK, Thalwitzer S, Wachter B, et al. Species-specific differences in Toxoplasma gondii, Neospora caninum and Besnoitia besnoiti seroprevalence in Namibian wildlife. Parasit Vectors. 2020;13 1:7.

Page 6/10 
18. Alvarez-Garcia G, Frey CF, Mora LM, Schares G. A century of bovine besnoitiosis: an unknown disease re-emerging in Europe. Trends Parasitol. 2013;29 8:407-15

19. Seltmann A, Webster F, Martins Ferreira SC, Czirjak GA, Wachter B. Age-specific gastrointestinal parasite shedding in free-ranging cheetahs (Acinonyx jubatus) on Namibian farmland. Parasitol Res. 2019;118 3:851-9.

20. Heinrich SK, Hofer H, Courtiol A, Melzheimer J, Dehnhard M, Czirják GÁ, et al. Cheetahs have a stronger constitutive innate immunity than leopards. Scientific reports. 2017;7 1:44837.

21. Ho MSY, Barr BC, Marsh AE, Anderson ML, Rowe JD, Tarantal AF, et al. Identification of bovine Neospora parasites by PCR amplification and specific small-subunit rRNA sequence probe hybridization. Journal of Clinical Microbiology. 1996;34:1203-8.

22. Schares G, Globokar Vrhovec M, Tuschy M, Joeres M, Barwald A, Koudela B, et al. A real-time quantitative polymerase chain reaction for the specific detection of Hammondia hammondi and its differentiation from Toxoplasma gondii. Parasit Vectors. 2021;14 1:78.

23. Slapeta JR, Koudela B, Votypka J, Modry D, Horejs R, Lukes J. Coprodiagnosis of Hammondia heydorni in dogs by PCR based amplification of ITS 1 rRNA: differentiation from morphologically indistinguishable oocysts of Neospora caninum. Vet J. 2002;163 2:147-54.

24. Schares G, Pantchev N, Barutzki D, Heydorn AO, Bauer C, Conraths FJ. Oocysts of Neospora caninum, Hammondia heydorni, Toxoplasma gondii and Hammondia hammondi in faeces collected from dogs in Germany. International Journal for Parasitology. 2005;35:1525-37.

25. Abel J, Schares G, Orzeszko K, Gasser RB, Ellis JT. Hammondia isolated from dogs and foxes are genetically distinct. Parasitology. $2006 ; 132$ 2:187-92.

26. Schares G, Heydorn AO, Cüppers A, Conraths FJ, Mehlhorn H. Hammondia heydorni-like oocysts shed by a naturally infected dog and Neospora caninum NC-1 cannot be distinguished. Parasitology Research. 2001;87 10:808-16.

27. Gjerde B, Dahlgren SS. Hammondia triffittaen. comb. of foxes ( Vulpes spp.): biological and molecular characteristics and differentiation from Hammondia heydorni of dogs. Parasitology. 2011;138 3:303-21.

28. Schares G, Basso W, Majzoub M, Cortes HC, Rostaher A, Selmair J, et al. First in vitro isolation of Besnoitia besnoiti from chronically infected cattle in Germany. Vet Parasitol. 2009;163 4:315-22.

29. Payne S, Ellis J. Detection of Neospora caninum DNA by the polymerase chain reaction. International Journal for Parasitology. 1996;26:347-51.

30. Talabani H, Asseraf M, Yera H, Delair E, Ancelle T, Thulliez P, et al. Contributions of immunoblotting, real-time PCR, and the Goldmann-Witmer coefficient to diagnosis of atypical toxoplasmic retinochoroiditis. Journal of Clinical Microbiology. 2009;47 7:2131-5.

31. Legnani S, Pantchev N, Forlani A, Zini E, Schares G, Balzer J, et al. Emergence of cutaneous neosporosis in a dog receiving immunosuppressive therapy: molecular identification and management. Vet Dermatol. 2016;27 1:49-e14.

32. Schares G, Maksimov A, Basso W, More G, Dubey JP, Rosenthal B, et al. Quantitative real time polymerase chain reaction assays for the sensitive detection of Besnoitia besnoiti infection in cattle. Vet Parasitol. 2011;178 3-4:208-16.

33. Constantin EM, Schares G, Grossmann E, Sauter K, Romig T, Hartmann S. [Studies on the role of the red fox (Vulpes vulpes) as a potential definitive host of Neospora caninum]. Berl Munch Tierarztl Wochenschr. 2011;124 3-4:148-53.

34. Hoffmann B, Depner K, Schirrmeier H, Beer M. A universal heterologous internal control system for duplex real-time RT-PCR assays used in a detection system for pestiviruses. J Virol Methods. 2006;136 1-2:200-9.

35. Nei M, Kumar S. Molecular evolution and phylogenetics. New York: Oxford University press; 2000.

36. Kumar S, Stecher G, Li M, Knyaz C, Tamura K. MEGA X: Molecular evolutionary genetics analysis across computing platforms. Mol Biol Evol. 2018;35 6:1547-9.

37. Dubey JP. Toxoplasmosis of animals and humans. 2nd edn. Boca Raton: CRC Press; 2010.

38. Pols JW. Studies on bovine besnoitiosis with special reference to the aetiology. Onderstepoort Journal of Veterinary Research. 1960;28 265-356.

39. Bigalke RD, Niekerk, J. W. van , Basson PA, McCully RM. Studies on the relationship between Besnoitia of blue wildebeest and impala, and Besnoitia besnoiti of cattle. Onderstepoort Journal of Veterinary Research. 1967;34 1:7-28.

40. Dubey JP, Hemphill A, Calero-Bernal R, Schares G. Neosporosis in animals. Boca Rotan: CRC Press; 2017.

41. Guay JM, Huot A, Gagnon S, Tremblay A, Levesque RC. Physical and genetic mapping of cloned ribosomal DNA from Toxoplasma gondii: primary and secondary structure of the $5 S$ gene. Gene. 1992;114 2:165-71.

42. Ogedengbe ME, Ogedengbe JD, Whale JCE, K., Juarez-Estrada MA, Barta JR. Molecular phylogenetic analyses of tissue coccidia (sarcocystidae; apicomplexa) based on nuclear 18s RDNA and mitochondrial COI sequences confirms the paraphyly of the genus Hammondia. Parasitology Open. 2016;2 e2:1-16.

43. Olias P, Schade B, Mehlhorn H. Molecular pathology, taxonomy and epidemiology of Besnoitia species (Protozoa: Sarcocystidae). Infect Genet Evol. 2011;11 7:1564-76.

44. Nilsson MA, Churakov G, Sommer M, Tran NV, Zemann A, Brosius J, et al. Tracking marsupial evolution using archaic genomic retroposon insertions. PLoS Biol. 2010;8 7:e1000436.

45. Spencer PBS, Yurchenko AA, David VA, Scott R, Koepfli K-P, Driscoll C, et al. The population origins and expansion of feral cats in Australia. J Hered. 2016;107 2:104-14.

\section{Tables}

Table 1. 
PCR targeted nine overlapping regions of the 18 S rDNA, the ITS-1 and part of the 5.8S rDNA. A variable number of plasmid clones per target was received and subsequently Sanger-sequenced. Sequences were not concatenated, but individually assessed by BLASTn. The top five hits of species using in BLASTn the option MaxScore are displayed. Due to the conserved primer regions, sequences of unrelated species, i.e. predominantly fungi, were identified in addition to sequences resembling sequences of coccidian parasite related or Besnoitia sp.-related species.

\begin{tabular}{|c|c|c|c|}
\hline $\begin{array}{l}\text { Relatedness } \\
\text { of } \\
\text { sequences }\end{array}$ & $\begin{array}{l}\text { Amplification } \\
\text { with primer } \\
\text { pairs }\end{array}$ & $\begin{array}{l}\text { Number } \\
\text { of } \\
\text { clones }\end{array}$ & $\begin{array}{l}\text { Top five species with highest identity and coverage in GenBank (number of sequences per organism, } \\
\text { percent coverage, percent identity) }\end{array}$ \\
\hline \multicolumn{4}{|l|}{$\begin{array}{l}\text { Besnoitia } \\
\text { sp.-related }\end{array}$} \\
\hline & $\begin{array}{l}\text { BbGS4F- } \\
\text { BdanjoRev }\end{array}$ & 3 & $\begin{array}{l}\text { B. oryctofelisi }(1,99-100,98.58-99.01), \text { B. darlingi }(1,99-100,98.31-98.73), \text { B. tarandi }(1,100,97.85-98.17) \text {, } \\
\text { B. besnoiti }(7,99-100,97.85-98.17), \text { B. bennetti }(1,99-100,97.69-98.03)\end{array}$ \\
\hline & JS4-TIM11 & 3 & $\begin{array}{l}\text { B. darlingi }(3,82-90,93.60-94.20) \text {, B. oryctofelisi }(2,77-80,93.42-93.91), \text { B. caprae }(1,100,87.02-88.03), B \text {. } \\
\text { besnoiti }(5,100,87.02-88.06), \text { B. akodoni }(1,76-77,92.52-92.97)\end{array}$ \\
\hline & 18S-5F-TIM11 & 3 & $\begin{array}{l}\text { B. darlingi }(1,92,95.75-96.02), \text { B. oryctofelisi }(1,89-90,95.93-96.19), \text { B. besnoiti }(7,99-100,91.41-91.82), B \\
\text { tarandi }(1,96-97,91.32-91.72), \text { B. bennetti }(1,93,91.04-91.46)\end{array}$ \\
\hline & JS4-TIM11 & 2 & $\begin{array}{l}\text { B. darlingi }(3,79-90,92.86-93.40) \text {, B. oryctofelisi }(2,75-78,92.73-92.97), \text { B. caprae }(1,100,86.44-86.81), B \text {. } \\
\text { besnoiti }(5,100,86.44-86.81), \text { bennetti }(1,100,86.21-86.60)\end{array}$ \\
\hline & JS4-TIM11 & 1 & $\begin{array}{l}\text { B. darlingi }(2,80-89,91.95-92.82), \text { B. oryctofelisi }(2,85-86,92.69-92.82), \text { B. akodoni }(1,83,91.72), B \text {. } \\
\text { neotomofelis }(1,83,90.72) \text {, B. bennetti }(1,100,85.54)\end{array}$ \\
\hline & $\begin{array}{l}\text { BbGS5F- } \\
\text { BbGS5R }\end{array}$ & 2 & $\begin{array}{l}\text { B. darlingi (2, 99-100, 99.31-99.54), B. oryctofelisi }(1,99-100,99.31-99.54), \text { B. jellisoni }(1,99-100,99.31- \\
99.54), \text { B. besnoiti }(12,100,99.09-99.31), B \text { tarandi }(2,100,98.86-99.31)\end{array}$ \\
\hline \multicolumn{4}{|l|}{$\begin{array}{l}\text { Coccidia- } \\
\text { related }\end{array}$} \\
\hline & $\begin{array}{l}\text { BbGS1F- } \\
\text { BbGS1R }\end{array}$ & 6 & $\begin{array}{l}\text { C. sp. ex. Aonyx cinereus }(1,99,99.17-99.67) \text {, C. belli }(8,63,99.17-99.67), \text { Cohioensis }(4,63-99,99.00- \\
99.50), \text { C. suis }(2,63-99,99.00-99.50), \text { Cystoisospora sp. }(1,63-99,99.00-99.50)\end{array}$ \\
\hline & $\begin{array}{l}\text { BbGS4F- } \\
\text { BbGS4R }\end{array}$ & 2 & $\begin{array}{l}\text { C. belli }(5,100,99.66), \text { C. timori }(1,100,99.66), \text { C. cf. ohioensis }(1,100,99.49), \text { H. triffitae }(1,100,99.33), H \text {. } \\
\text { heydorni }(1,100,99.33)\end{array}$ \\
\hline & $\begin{array}{l}\text { BbGS6F- } \\
\text { BbGS6R }\end{array}$ & 2 & $\begin{array}{l}\text { C. ohioensis }(4,97-100,99.76-99.53), \text { C. belli }(5,100,99.30-99.53), \text { C. timori }(1,100,99.06), \text { C. canis }(2,97 \text {, } \\
99.76) \text {, C. suis }(2,97,99.76)\end{array}$ \\
\hline & $\begin{array}{l}\text { BbGS2F- } \\
\text { BbGS2R }\end{array}$ & 1 & $\begin{array}{l}\text { C. sp. ex. Aonyx cinereus }(1,100,100.00), \text { C. canis }(2,100,100.00), \text { C. ohioensis }(3,100,100.00), \text { C. suis }(2, \\
100,100.00), \text { C. laidlawi }(1,100,100.00)\end{array}$ \\
\hline & $\begin{array}{l}\text { BbGS3F- } \\
\text { BbGS3R }\end{array}$ & 1 & $\begin{array}{l}\text { B. besnoiti }(4,100,99.81) \text {, B. darlingi }(1,100,99.81), \text { T. gondii }(19,100,99.81) \text {, H. heydorni }(1,100,99.81) \text {, } \\
\text { H. hammondi }(1,100,99.81)\end{array}$ \\
\hline & $\begin{array}{l}\text { BbGS3F- } \\
\text { BbGS3R }\end{array}$ & 1 & $\begin{array}{l}\text { C. ohioensis }(4,100,99.81), \text { C. suis }(2,100,99.81), \text { C. belli }(2,100,99.81), \text { Cystoisospora sp. }(1,100,99.81) \text {, } \\
\text { C. timori }(1,100,99.81)\end{array}$ \\
\hline \multicolumn{4}{|l|}{$\begin{array}{l}\text { Unrelated to } \\
\text { coccidia }\end{array}$} \\
\hline & $\begin{array}{l}\text { BbGS6F- } \\
\text { BbGS6R }\end{array}$ & 1 & $\begin{array}{l}\text { Thecaphora spilanthes }(1,70,93.64) \text {, uncultured basidiomycete }(1,67,92.89), \text { Exobasidium rhododentri }(1, \\
70,90.36) \text {, uncultured Ceriporiopsis }(1,72,89.44) \text {, Exobasidium rostrupli }(1,70,90.07),\end{array}$ \\
\hline & $\begin{array}{l}\text { BbGS6F- } \\
\text { BbGS6R }\end{array}$ & 1 & $\begin{array}{l}\text { T. spilanthes }(1,45,98.79) \text {, Arabidopsis lyrate }(1,56,99.09) \text {, Scyliorhinus canicula }(1,34,99.09), \text { uncultured } \\
\text { archeon }(1,40,99.08), \text { uncultured bacterium }(4,40,99.08)\end{array}$ \\
\hline & $\begin{array}{l}\text { BbGS4F- } \\
\text { BbGS4R }\end{array}$ & 1 & $\begin{array}{l}\text { Helminthosporium hispanicum }(2,100,89.92), H \text {. tiliae }(2,100,89.92), H \text {. quercium }(2,100,89.92), H \text {. } \\
\text { austriacum }(2,100,89.92) \text {, H. velutium }(3,100,89.92)\end{array}$ \\
\hline & $\begin{array}{l}\text { BbGS4F- } \\
\text { BbGS4R }\end{array}$ & 1 & $\begin{array}{l}\text { Thecaphora saponariae }(1,75,99.65), \text { Thecaphora amaranthi }(1,76,90.12) \text {, Exobasidiomycetes } \mathrm{sp} .(1,78, \\
89.09) \text {, Tilletiopsis washingtonensis }(1,78,88.76) \text {, Tilletiopsis sp. }(1,78,88.76)\end{array}$ \\
\hline
\end{tabular}

Table 2.

Estimates of evolutionary divergence between the ITS-1 rDNA region sequences of "Besnoitia-acinonyx" (MW468050; this study) and other Besnoitia spp. [B. besnoiti (AY833646), B. jellisoni (AF076860), B. neotomofelis (HQ909085), B. akodoni (AY545987), B. oryctofelisi (AY182000, GU479632), B. darlingi (AF489696, MF872605, GU479631, HQ163919], T. gondii (L49390), N. caninum (AY259040), H. heydorni (AY189897), and H. triffitae (KJ396594). The number of base substitutions per site between sequences are shown in the table (pairwise distance). Analyses were conducted using the Maximum Composite Likelihood model [37]. This analysis involved 15 nucleotide sequences. All codon positions $\left(1^{\text {st }}, 2^{\text {nd }}, 3^{\text {rd }}\right.$, Noncoding) were included. All ambiguous positions were removed for each sequence pair (pairwise deletion option). There were 425 positions in the final dataset. Evolutionary analyses were conducted in MEGA $X$ [36]. Pairwise distances $>0.5$ are underlined, distances $<0.1$ are written with italic letters. The two sequences of $B$. oryctofelisi revealed the same values for all cells, as did three of the four $B$. darlingi sequences. The fourth sequence (Bdar2, MF872605) revealed slightly different values which are shown in brackets. 


\begin{tabular}{|c|c|c|c|c|c|c|c|c|c|c|c|}
\hline Isolate & $\begin{array}{l}\text { Besnoitia- } \\
\text { acinonyx }\end{array}$ & $\begin{array}{l}T . \\
\text { gondii }\end{array}$ & $\begin{array}{l}N . \\
\text { caninum }\end{array}$ & $\begin{array}{l}\text { H. } \\
\text { heydorni }\end{array}$ & $\begin{array}{l}\text { H. } \\
\text { tiffitae }\end{array}$ & $\begin{array}{l}\text { B. } \\
\text { besnoiti }\end{array}$ & $\begin{array}{l}B . \\
\text { jellisoni }\end{array}$ & $\begin{array}{l}\text { B. } \\
\text { neotomo- } \\
\text { felis }\end{array}$ & $\begin{array}{l}\text { B. } \\
\text { akodoni }\end{array}$ & $\begin{array}{l}\text { B. orycto- } \\
\text { felisi }(\mathrm{n}=2 \\
\text { sequences) }\end{array}$ & $\begin{array}{l}\text { B. darlingi } \\
\text { ( } n=4 \\
\text { sequences) }\end{array}$ \\
\hline $\begin{array}{l}\text { Besnoitia- } \\
\text { acinonyx }\end{array}$ & 0.000 & & & & & & & & & & \\
\hline T. gondii & $\underline{0.595}$ & 0.000 & - & - & - & - & - & - & - & - & - \\
\hline N. caninum & $\underline{0.544}$ & 0.257 & 0.000 & & & & & & - & - & - \\
\hline H. heydorni & $\underline{0.542}$ & 0.288 & 0.269 & 0.000 & - & & - & & - & - & - \\
\hline H. triffitae & $\underline{0.531}$ & 0.297 & 0.268 & 0.011 & 0.000 & & & & & - & - \\
\hline B. besnoiti & 0.234 & $\underline{0.530}$ & 0.492 & $\underline{0.534}$ & $\underline{0.523}$ & 0.000 & & & & - & - \\
\hline B. jellisoni & 0.095 & $\underline{0.674}$ & $\underline{0.674}$ & $\underline{0.608}$ & $\underline{0.596}$ & 0.279 & 0.000 & & & - & - \\
\hline B. neotomo-felis & 0.095 & $\underline{0.692}$ & $\underline{0.657}$ & $\underline{0.610}$ & $\underline{0.598}$ & 0.288 & 0.026 & 0.000 & & - & - \\
\hline B. akodoni & 0.079 & $\underline{0.617}$ & $\underline{0.628}$ & $\underline{0.570}$ & $\underline{0.558}$ & 0.294 & 0.063 & 0.063 & 0.000 & & \\
\hline $\begin{array}{l}\text { B. oryctofelisi } \\
\text { ( } n=2 \text { sequences) }\end{array}$ & 0.069 & $\underline{0.639}$ & $\underline{0.609}$ & $\underline{0.540}$ & $\underline{0.529}$ & 0.268 & 0.054 & 0.054 & 0.030 & 0.000 & \\
\hline $\begin{array}{l}\text { B. darlingi }(n=4 \\
\text { sequences) }\end{array}$ & $\begin{array}{l}0.064 \\
(0.069)\end{array}$ & $\frac{0.645}{(\underline{0.654})}$ & $\frac{0.629}{(\underline{0.638)})}$ & $\frac{0.571}{(\underline{0.578})}$ & $\frac{0.559}{(\underline{0.567)})}$ & $\begin{array}{l}0.271 \\
(0.277)\end{array}$ & $\begin{array}{l}0.049 \\
(0.053)\end{array}$ & $\begin{array}{l}0.048 \\
(0.053)\end{array}$ & $\begin{array}{l}0.026 \\
(0.030)\end{array}$ & $\begin{array}{l}0.013 \\
(0.017)\end{array}$ & $\begin{array}{l}0.000 \\
(0.004)\end{array}$ \\
\hline
\end{tabular}

\section{Figures}

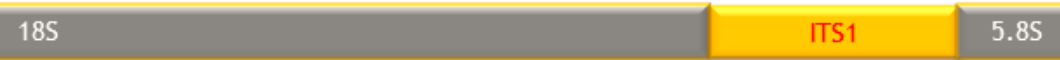

BbGS6F-BbGS6R

\section{BbGS2F-BbGS2R}

\section{BbGS4F-BbGS4R}

\section{BbGS3F-BbGS3R}

JS4-TIM11

\section{BbGS5F-BbGS5R}

\section{BbGS4F-BdanjoRev}

\section{S-5F-TIM11}

\section{Figure 1}

Overview on PCR fragments and primer names to assess rDNA sequences of B. darlingi-like parasites (named "Besnoitia-acinonyx" for this study) and related organisms in faeces of a Namibian cheetah. Amplicons coloured green revealed sequences closely related to B. darlingi-like parasites (Table 1); amplicons coloured yellow revealed sequences related to additional coccidia (Table2). Details on primer sequences in Additional file 1: Table S1. 

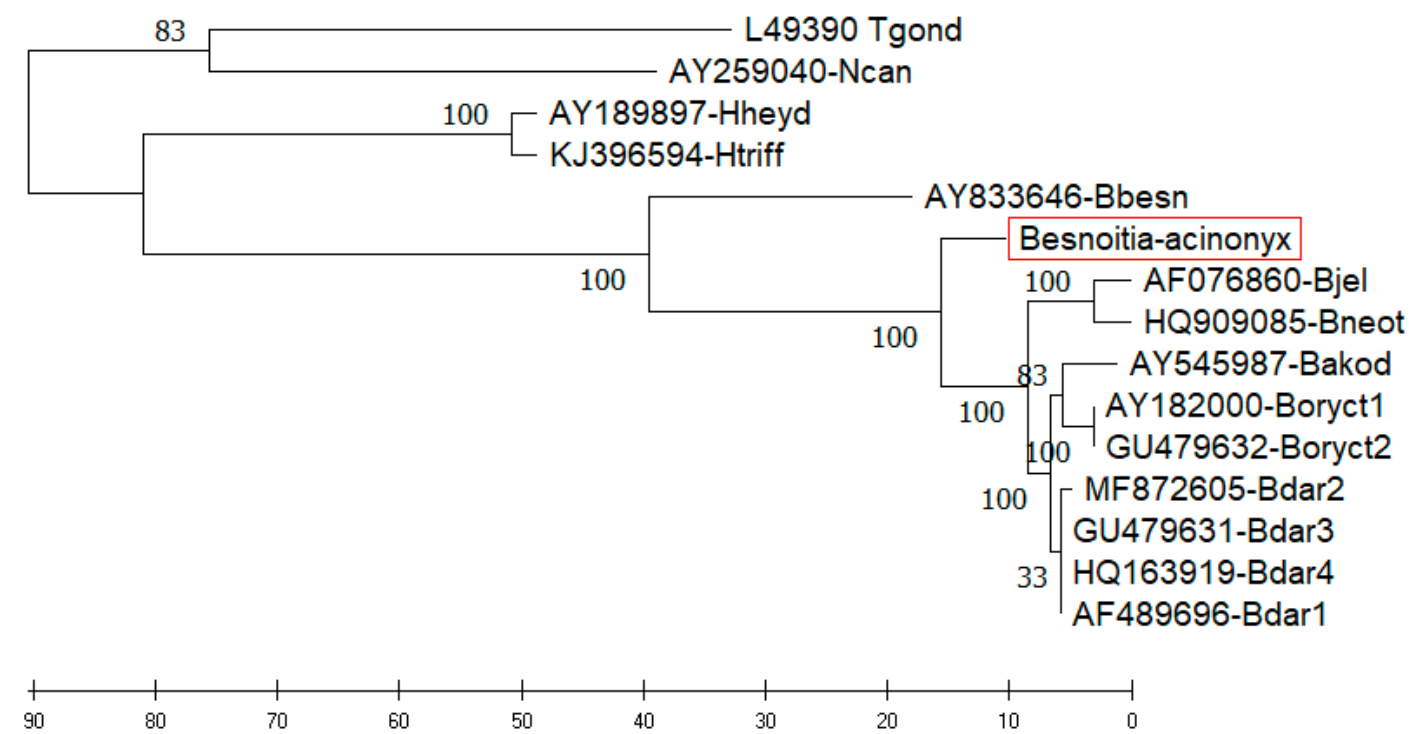

Figure 2

GenBank sequences of N. caninum (Ncan, AY259040), T. gondii (Tgond, ME49, L49390), H. heydorni (Hheyd, AY189897), H. triffitae (Htriff, KJ396594), B. besnoiti (Bbesn, AY833646), "Besnoitia-acinonyx" (MW468050; this study; Additional file 2: Text S1), B. jellisoni (Bjel, AF076860), B. neotomofelis (Bneot, HQ909085), B. akodoni (Bakod, AY545987), B. oryctofelisi \#1 (Boryct1, AY182000), B. oryctofelisi \#2 (Boryct2, GU479632), B. darlingi \#1 (Bdar1, AF489696), B. darlingi \#2 (Bdar2, MF872605), B. darlingi \#3 (Bdar3; GU479631), B. darlingi \#4 (Bdar4, HQ163919) were subjected to evolutionary history analysis using the Maximum Parsimony (MP) method. The consensus tree inferred from 6 most parsimonious trees is shown. Branches corresponding to partitions reproduced in less than $50 \%$ trees are collapsed. The consistency index is $0.912(0.866)$, the retention index is $0.910(0.910)$, and the composite index is 0.830 (0.788) for all sites and parsimony-informative sites (in parentheses). The MP tree was obtained using the Subtree-Pruning-Regrafting (SPR) algorithm [35] with search level 0 , in which the initial trees were obtained by the random addition of sequences (10 replicates). The tree is drawn to scale, with branch lengths calculated using the average pathway method [35] and are in the units of the number of changes over the whole sequence. The analysis involved 15 nucleotide sequences. All codon positions (1st, 2nd, 3rd, Noncoding) were included. There were 425 positions in the final dataset. Evolutionary analyses were conducted in MEGA X [36].

\section{Supplementary Files}

This is a list of supplementary files associated with this preprint. Click to download.

- BdarAcinonyxGraphAbstr20210208.tif

- BdarAcinonyxTableS120210209.docx

- BdarAcinonyxTXTS120210209.docx 